\title{
Strategies Used by Grade 6 Learners in the Multiplication of Whole Numbers in Five Selected Primary Schools in the Kavango East and West Regions
}

\author{
Alex Mbonabi ILUKENA ${ }^{1}$, Christina Nyarai UTETE $^{1}$ \& Chosi KASANDA $^{1}$ \\ ${ }^{1}$ Department of Mathematics, Science and Sport Education, Faculty of Education, University of Namibia, \\ Namibia \\ Correspondence: Alex Mbonabi ILUKENA, University of Namibia, Rundu Campus, Namibia.
}

Received: January 24, 2019

Accepted: July 1, 2019 Online Published: February 18, 2020

doi:10.5539/ies.v13n3p65

URL: https://doi.org/10.5539/ies.v13n3p65

\begin{abstract}
This research paper reports strategies used by Grade 6 learners in multiplying whole numbers in five selected primary schools in Kavango East and West regions. A total of 200 learners' mathematics exercise books were analysed in order to identify the commonly used strategies by learners in multiplying whole numbers. A total of ten teachers teaching grade 6 mathematics were also requested to complete a questionnaire which required them to indicate the strategies that they employed in class when teaching multiplication of whole numbers. The teachers indicated that they used a variety of strategies including repeated addition, complete-number (Including doubling), partitioning and compensation to teach multiplication of whole numbers. The results also disclosed that the majority of the learners' mathematics exercise books reflected the use of the traditional method of repeated addition contrary to the teachers' claims. It was also found that a few of the learners used other strategies such as long method, short method and learner "invented" strategies. Additionally, the mathematics curriculum for upper primary learners (Grade 4-7 mathematics syllabus) requires learners to use paper and pencil algorithms to carry out multiplication of whole numbers without calculators (Ministry of Education, Arts \& Culture [MoEAC], 2015, p. 2). However, at Grade 6, learners were expected to use paper and pencil algorithms to multiply numbers within the range 0-100000. Analysis of the learners' exercise books indicated that the majority were not able to multiply a two digit by a single digit, a two digit by a two digit and a three digit by a two digit number.
\end{abstract}

Keywords: grade 6 learners, multiplication, whole numbers, multiplication table, repeated addition, multiple, product, partial sum, sum, distributive law

\section{Introduction and Background}

The Kavango East and West regions are allocated in North and East of Namibia. They share borders with Angola, Zambia and Botswana. The two regions form part of Namibia's fourteen political regions since Kavango region was split into two in 2013. The problem under study emerged after observing several mathematics lessons during School Based Studies/Teaching Practice (SBS/TP) from 2014 and after attending the 10th National Annual Mathematics Congress at Swakopmund and University of Namibia [UNAM]: Rundu campus research day in 2015. At the congress, lower (grades 1-4) and upper (grades 5-7) mathematics teachers expressed frustrations at learners' lack of fluency in basic multiplication. This lack of fluency affects other mathematics topics such as fractions, division, ratio, proportion and measurement conversion that require multi-digit multiplication. Furthermore, a research carried out by Mateya, Utete, \& Ilukena (2016) shows that performance in mathematics at Junior Secondary Certificate (JSC) and National Secondary School Certificate (NSSC) levels is not impressive due to learners not mastering basic mathematical concepts and competences (p. 165). It emerged from the same study that the same cohort of learners sat for JSC in 2011 and NSSC in 2013 and there was no apparent improvement in both results. The study of (Mateya et al., 2016) also revealed that upper primary and high school mathematics teachers skip topics that they are not competent in. It is against this backdrop that this research was carried out. The research was designed to find out if the poor performance was emanating from upper primary hence the focus was to find out strategies used by Grade 6 learners in multiplying whole numbers. It is important to know and comprehend strategies used in multiplying whole numbers as they are fundamental in bridging the gap among advanced mathematics, day to day mathematics and other fields that require mathematics. It became evident that the majority of the learners in the two Kavango regions experience challenges in answering both oral and written 
multiplication problems.

Research carried out by Kumon (2012) indicated that kindergarten aged children in Australia solve a variety of multiplication and division problems by combining direct modeling with counting and grouping skills and with strategies based on addition and subtraction. Kumon's study has also shown that multiplication and division skills can be applied to real life situations. From an early stage children share things among themselves, handle money when buying items, and also share food in portions. This indicates that they are beginning to build up their multiplication and division skills as part of their everyday life. The introduction to these mathematical ideas at an early stage might make children gain confidence in learning and using mathematics so as to enable them use the acquired mathematical ideas and problem solving skills in the wider world.

\subsection{Objectives of the Study}

- To find out to what extent the syllabi cover the conceptual understanding of multiplication and its applications.

- To find out strategies used to teach multiplication of whole numbers at upper primary level.

- To find out to what depth multiplication is being taught at upper primary level.

\subsection{Literature Review}

Mathematics is perceived as a creative human endeavour, growing, changing and fallible (Lerman, 1994, p. 98). If mathematics is perceived in this way, then the role of the mathematics teacher is to instill achievement in learners (Tooley, 1990 as cited by Lerman, 1994) by creating learning opportunities, developing supporting materials which in turn assist them to choose suitable content and all the learning outcomes (p. 99). Although the role of mathematics in its application has changed, mathematics teachers should not only rush to cover the syllabus, but to teach for conceptual understanding, and enhance the five mathematical proficiency skills which include; conceptual understanding, procedural fluency, strategy competency, adaptive reasoning and productive disposition (Kilpatrick, Swafford, \& Findell, 2001, as cited by Mateya et al., 2016, p. 109). The five mathematical proficiency skills are not conspicuously stated in the Namibian mathematics curriculum, but have been interwoven in the learning objectives and competencies (Ministry of Education, Arts \& Culture [MoEAC], 2016, pp. 14-49). Therefore, for the Namibian primary school mathematics teachers to be effective, they need to carry out research in their area of specialisation so that they can interpret and design mathematics learning programmes that supplement the syllabus. These learning programmes should encompass four basic operations, addition, subtraction, multiplication and division with the main focus being on multiplication of facts. The teaching should be based on partial products algorithm and other strategies rather than the standard algorithm as traditionally known. In this way the mathematics teachers will be laying a firm foundation for their learners in learning mathematics. As research by (Mateya et al., 2016) has shown that mathematics learners are not adequately prepared in mathematics at junior secondary as well as at national school secondary certificate levels. Although research revealed multiple factors contributing to these deficiencies, one key factor was automaticity of learners' multiplication facts (Kilpatrick, Swafford, \& Findell, 2001). For a learner to become a better problem solver entails decreasing that particular learner's cognitive load in order to increase the amount of energy spent on solving the problem versus trying to remember facts (Nelson, Burns, Kanive, \& Ysseldyke, 2013 as cited by Brendefur, Strother, Thiede, \& Appleton, 2015, p. 142). Thus flexibility leads to fluency and efficiency with various numbers and across contexts.

Multiplication is defined as a mathematical operation in which two numbers are combined to give a third number (the product), denoted by $\mathrm{a} \times \mathrm{b}$ or $\mathrm{a}^{*} \mathrm{~b}$ or (for symbols) by ab (Southern et al., 1989, p. 224). Multiplication of integers can be regarded as repeated addition for example $2 \times 3=6$ is the integer obtained by adding two 3 's ( $3+3$ $=6$ ). This is the same as adding three 2 's $(2+2+2=6)$, a demonstration of the commutative nature of multiplication of numbers. Furthermore, multiplication can be regarded as the process of multiplying one number (the multiplier) by another (the multiplicand), although the results are the same whichever number is chosen for the multiplicand or multiplier. Fractions are multiplied by multiplying the numerators and denominators separately, i.e., $\mathrm{a} / \mathrm{b} \times \mathrm{c} / \mathrm{d}=\mathrm{ac} / \mathrm{bd}$, while polynomials are multiplied by using the distributive law (also expansion). Complex numbers can also be multiplied using the same concept of the multiplicand and multiplier. In addition, the concept of multiplication has been extended to other entities, such as vectors, sets (Cartesian product) and matrices (Freitag, 2014, p. 190). Multiplication facts are not limited to integers only or mathematics but to other subjects such as Physics, Biology, Geography, Engineering to mention but a few. This therefore indicates that fluency with multiplication facts is important and requires deeper understanding of concepts, flexibility and, ready use of computation skills through a variety of applications. Learners without sound knowledge of basic mathematical facts or a way of figuring them out are prone to poor performance in solving problems. To enhance the performance of learners in computational skills in multiplication the learners should first learn to add and subtract, 
and then they can begin to work with multiplication and division. In support of this assertion Freitag (2014) and Van de Walle, Karp, \& Bay-Williams (2012) found that some textbooks and teachers have moved from presenting concepts of addition and multiplication straight to memorisation of facts, skipping the process of developmental strategies. Learners need to first develop an intuitive understanding of the operations and computation basic facts before they multiply and divide large numbers. Freitag (2014, p. 190) suggests two approaches to whole - number multiplication:

Repeated-Addition approach, in which learners when working with addition questions encounter addends (or Augends) of the same numbers such as $4+4+4+4+4$ and $7+7+7+7+7$. In such a situation they should condense these sums by using multiplication as a notional short cut to repeated addition. For instance, $4+4+4+$ $4+4$ and $7+7+7+7$ are written as $5 \times 4$ and $4 \times 7$ respectively. This is done by using the definition of whole number multiplication (Repeated - Addition approach) whereby if $a$ and $b$ are any whole numbers with $a \neq 0$, then $a \times b=b+b+b+\ldots+b$, a times. If $a=0$, then $0 \times b=0$ for all $b$. Research by Freitag (2014) has also shown that the repeated - addition approach to multiplication can be modeled in a number of concrete ways such as set model, the array model, and the number line model (p.190). Another way to approach whole - number multiplication is to use cartesian product of two sets. By definition: If $a$ and $b$ are any whole numbers where $a=n(A)$ and $b=n(B)$, then $a \times b=n(A \times B)$. The Cartesian-product approach to multiplication can also be modeled in two ways: with sets and with tree diagrams (p. 194).

Research has further shown that the developmental nature of basic facts mastery on teaching basic facts requires essential understanding that learners progress through stages that eventually result in "just knowing" that $4+2$ is 6 or that $3 \times 7$ is 21 (Van de Walle, Karp, \& Bay-Williams, 2010, p. 167). This notion encompasses what Baroody (2006) describes as three phases for basic fact mastering which are: counting strategies-using object counting for example blocks, fingers or verbal counting to determine the answer; reasoning strategies-using known information to logically determine an unknown combination as well as mastery-efficient (fast and accurate) production of answers (p. 22). In addition, other researchers (Baroody, 2006; Brownell \& Chazal, 1935; Carpenter \& Moser, 1984; Fuson, 1992; Henry \& Brown, 2008 as cited by Van de Walle et al., 2010) found that basic fact mastering is dependent on the development of reasoning strategies. This mastery is essential if learners are to become proficient at solving basic mathematics problems. This is contrary to Tirhaji (1965 as cited in Lerman, 1994) on the Vedic method of long multiplication dated back to Vedic sutras from $1200 \mathrm{BC}$ and possibly as far back as $3000 \mathrm{BC}$, whereby the figures are written once and the calculation done in one stage (Lerman, 1994, p. 97). This method that used patterns that were visually appealing and had many potentially interesting aspects left out to either the learners, investigators other researchers to imagine and investigate further.

\subsection{Approaches to Facts Mastery Teaching}

The approaches that can be employed to help learners master the basic mathematics facts include:

\section{1) Memorising facts}

Research carried by (Van de Walle et al., 2012) found out that some textbooks and teachers have moved away from presenting concepts of addition and multiplication straight to memorisation of facts, skipping the process of developmental strategies. However, the reality is that the majority of fourth or fifth grade learners have not mastered addition and subtraction facts, and that learners at upper primary and beyond do not know their multiplication facts. This method does not work well (Brownell \& Chazal, 1935 as cited in Van de Walle et al., 2012). Brownell and Chazal (1935, p. 17) concluded that children develop a variety of different thought processes or strategies for basic facts in spite of the amount of isolated drill that they experience. Moreover, Baroody (2006) notes that this approach to basic facts instruction works against the development of the five strands of mathematics proficiency pointing out the following limitations: inefficiency: too many facts to memorise; Inappropriate: learners misapply the facts and do not check their work and Inflexibility: Learners do not learn flexible strategies for finding the sum or product and therefore continue to use counting as a means of obtaining the answer. As indicated by Henry \& Brown (2008) teachers who rely heavily on textbooks, which focus on memorizing basic facts strategies, have learners with lower number sense proficiency.

\section{2) Explicit strategy instruction}

Teachers in the last three decades have resorted to showing learners an efficient strategy that is applicable to a collection of basic mathematics facts. Learners in return practice the strategy as it was shown or presented to them by the mathematics teacher. There is evidence to indicate that such a method can be effective (Henry \& Brown. 2008). The key is to help learners see the possibilities and then let them choose strategies that will assist them get to the solution without counting. 


\section{3) Guided invention}

This strategy is based on the notion that many of the strategies that are efficient will not be developed by all learners without some guidance from the teacher or other knowledgeable learners or experts (Gravemeijer \& van Galen, 2003 as cited by Brendefur \& Strother, 2011, p. 6; Vygotsky, 1978). Class discussions based on learners' solutions towards problems, and other tasks as well as games (such askudota,nhodo,wera) will bring a variety of strategies into the classroom. The task of the teacher is to design tasks and problems that promote the invention of effective strategies by learners and to make sure that these strategies are clearly articulated and shared in the classroom. This method reinforces reasoning strategies that help learners move away from counting and become more efficient in performing basic calculations, until they are able to recall facts quickly and correctly. On a daily basis the teacher should pose short word problems or questions that require critical thinking for learners to realise that if they do not know a fact, they can fall back on mathematics reasoning strategies such as multiplying mentally.

Furthermore, multiplication facts can also be mastered by relating new facts to existing knowledge, as Baroody (2006) and Wallace and Gurganus (2005 as cited by Wilson, McLaughlin, \& Bennett, 2016. p. 24) found that using a problem - based approach and focusing on reasoning strategies is important for developing mastery of the multiplication and related division facts. It is important that learners completely understand the commutative property as it develops their mathematical thinking by using representations, including drawing and using objects. Furthermore, some learners may immediately see the connection between the commutative property of addition and that of multiplication. This can be visualised by using areas model arrays.

Other strategies for learning single-digit multiplication facts are given below and will be discussed in detail later on:

- The finger - multiplication technique. This technique has its roots back to the middle ages in the earlier twentieth century by Russian and French peasants when finger counting was a regular means of communicating arithmetic information (Kolpas, 2002, p. 247; National Council of Teachers of Mathematics, 1989, p. 122).

- Strategy centred on properties of whole - number multiplication. This strategy is based on the definition of whole - number multiplication and uses whole - number addition and multiplication that satisfy the closure property, commutative property, associative property, and identity property.

- Zero multiplication property: Freitag (2014) has shown that some teachers have challenges in explaining why the zero multiplication property is true to learners. The Zero multiplication is interpreted using examples in terms of repeated addition. For instance, $8 \times 0$ can be interpreted as adding zero to itself 8 times: $8 \times 0=0+0+0+0+0+0+0+0=0$. In reverse, $0 \times 8$ can be interpreted as adding 8 to itself zero times so not one 8 is put into the sum, this results in getting the answer zero (0).

Once learners have used the different approaches and models to help them understand multiplication, they can turn to a multiplication table of single-digit multiplication facts to help them master all 100 single-digit multiplication facts.

\begin{tabular}{|r|r|r|r|r|r|r|r|r|r|r|}
\hline$\times$ & $\mathbf{1}$ & $\mathbf{2}$ & $\mathbf{3}$ & $\mathbf{4}$ & $\mathbf{5}$ & $\mathbf{6}$ & $\mathbf{7}$ & $\mathbf{8}$ & $\mathbf{9}$ & $\mathbf{1 0}$ \\
\hline $\mathbf{1}$ & 1 & 2 & 3 & 4 & 5 & 6 & 7 & 8 & 9 & 10 \\
\hline $\mathbf{2}$ & 2 & 4 & 6 & 8 & 10 & 12 & 14 & 16 & 18 & 20 \\
\hline $\mathbf{3}$ & 3 & 6 & 9 & 12 & 15 & 18 & 21 & 24 & 27 & 30 \\
\hline $\mathbf{4}$ & 4 & 8 & 12 & 16 & 20 & 24 & 28 & 32 & 36 & 40 \\
\hline $\mathbf{5}$ & 5 & 10 & 15 & 20 & 25 & 30 & 35 & 40 & 45 & 50 \\
\hline $\mathbf{6}$ & 6 & 12 & 18 & 24 & 30 & 36 & 42 & 48 & 54 & 60 \\
\hline $\mathbf{7}$ & 7 & 14 & 21 & 28 & 35 & 42 & 49 & 56 & 63 & 70 \\
\hline $\mathbf{8}$ & 8 & 16 & 24 & 32 & 40 & 48 & 56 & 64 & 72 & 80 \\
\hline $\mathbf{9}$ & 9 & 18 & 27 & 36 & 45 & 54 & 63 & 72 & 81 & 90 \\
\hline $\mathbf{1 0}$ & 10 & 20 & 30 & 40 & 50 & 60 & 70 & 80 & 90 & 100 \\
\hline
\end{tabular}

Figure 1. Multiplication table from 1 to 10 
The findings from countries such as Japan shifted from the traditional classroom that focused on the teachers' instructions on teaching multiplication to a learner-centred approach that engages learners in mathematics activities. This was a major reform in the Japanese education system in the learning and teaching of mathematics during the 1970s and 1980s (Takahashi, 2000, 2006). In support of Takahashi's findings, Freitag (2014) found that teaching mathematics using an instructional method such as lecture method may seem easy for the teachers, but then learners are passively listening to the teachers in this way the learners' opportunities to understand mathematical multiplication concepts and procedures are not maximised.

In addition, there is also a cultural dimension in teaching of multiplication facts called Gelosia multiplication method that involve multiple digit multiplication developed by Arab mathematicians around the thirteenth century and later introduced into Europe where it became known as multiplication "per Gelosia" or "by jealous" the name coming from the grid on which it was carried out (Winter, 2006, p. 203; Ifrah, 1988). The grid resembles the wooden or metal lattice. It is in context method, effectively, easier to use and give background meaning to useful mathematics ideas that enhance learners' mastery of multiplication facts.

In order to enhance multiplication facts learners need to be involved in effective instructional approaches designed to create interest and stimulate creativeness in multiplication lessons through learners "collaborative work. However, findings from the Namibian mathematics curriculum revealed that mental arithmetic calculations strategies need not to be confused with basic facts knowledge such as multiplication tables and number bonds which are missing in grades 4-7 mathematics syllabuses (MoEAC, 2016, p.70). Furthermore, the mathematics syllabi require the learners to apply commutative property of multiplication, for example $3 \times 6=6 \times 3=18$ as well as associative property of multiplication for example $4 \times 11 \times 2=11 \times 2 \times 4=88$. It is important that learners master the multiplication facts, as Wallace \& Gurganus (2005 as cited by Wilson, McLaughlin, \& Bennett, 2016) indicated that learners without either sound knowledge of their basic facts or way of figuring them out are at a profound disadvantage in their subsequent mathematics learning and achievement.

\subsection{Theoretical Framework}

The spiral curriculum theoretical framework in this study is informed by Bruner, 1960. The spiral curriculum allows students to revisit topics over time iteratively and hence helps them build competence (Harden \& Stamper, 1999, p. 141). Subject topics are met with increasing complexity as the learner moves up the educational ladder. In the process new knowledge is acquired upon previously learnt knowledge. The Namibian Mathematics Upper Primary curriculum (Grade 4-7) is based on the notion of the spiral curriculum. Prerequisite knowledge and skills are taught and are supposed to be mastered first in order to provide linkages between each lesson as learners move upwards from one grade to the next that is, learners are exposed to concepts at a lower level and these are encountered at a more detailed and complex level later on in their studies. As the learners move from one grade to the next; they encounter the same content, but at a higher level.

\section{Research Methodology}

\subsection{Informants}

The ten mathematics teachers (two from each school) in the study were from five different upper primary schools that were accessible to the researchers. All informants were informed about the confidentiality and voluntary basis of their participation.

\subsection{Sampling Procedures}

A simple random sample, which is a random sample type of design, was used. Class attendance registers were used to sample the learners' exercise books. The sampling was done by numbering the learners on the class attendance register using three digits numbers per school. The exercise books were picked at intervals of 10 from a population of 2000 while the population of ten mathematics teachers was not sampled as they were the only ones teaching subject.

\subsubsection{Sample Size}

The sample size of exercise books was determined by calculating $10 \%$ of the total number of exercise books per school as illustrates in the table below. 
Table 1. Sample size per school

\begin{tabular}{ccc}
\hline School & Total number of exercise books & $10 \%$ of exercise books \\
\hline A & 430 & 43 \\
B & 420 & 42 \\
C & 350 & 35 \\
D & 440 & 44 \\
E & 360 & 36 \\
Total & 2000 & 200 \\
\hline
\end{tabular}

The ten mathematics teachers also served as the sample size.

\subsubsection{Measures and Covariates}

The data was collected using questionnaires, document analysis, interactions with various stakeholders and observations. Questionnaires that contained both objective and open-ended items were administered to the ten grade 6 mathematics teachers. The teachers honestly and earnestly answered all the items on the questionnaires and returned within the time frame that was given. The upper primary mathematics syllabi, grade 5-7 and 200 learners' mathematics exercise books were perused and analysed to find out different strategies employed by mathematics teachers to teach the multiplication of whole numbers and how learners interpreted those strategies. Classroom observations and interactions with various participants were carried out how multiplication of whole numbers is computed.

\subsubsection{Research Design}

A mixed method that complements qualitative and quantitative approaches was used to collect data.

\section{Findings and Discussions}

This section presents the findings of the research study in relation to the classrooms observations, document analysis, interactions and questionnaires on how to multiply whole numbers.

\subsection{Classroom Observation}

Classroom observation findings revealed that learners encountered difficulties with multiplication of whole numbers on the chalkboard as well as in their exercise books. It was evident that learners were unable to multiply a two digit by a single digit, a two digit by a two digit and a three digit by a two digit number. It also emerged that learners did not have copies of multiplication tables taped on their desktops and they disregarded the multiplication table printed at the back of their mathematics exercises books for easy reference when solving multiplication facts questions of up to 10 by 10 at Grade 4 level and 12 by 12 at Grade 5-7 levels to avoid the practice of making tally marks when counting.

The researchers further observed that learners struggled with mathematics class activities that dealt with conceptual understanding, procedural fluency, strategic competency, adaptive reasoning and productive disposition in multiplication of whole numbers. This concurs with the findings of Mateya et al. (2016) who concluded that mathematics teachers should incorporates the five mathematical proficiency strands in their teaching for conceptual understanding (p. 109). Furthermore, the findings revealed that learners in the study struggled to master multiplication facts which were already introduced in earlier grades due to lack exposure to a variety of strategies and that they are required to memorize the multiplication facts. Some of strategies that teachers could employ are multiplying using Fingers, Area model, Cartesian product approach to enhance their understanding of basic multiplication facts. Developing multiplication table fluency up to 12 by 12 requires a balanced connection between conceptual understanding and computational proficiency. Fluency with multiplication facts includes the deep understanding of concepts and flexibility in the ready use of computation skills across a variety of applications.

\subsection{Document Analysis}

The findings from the analysed documents revealed the following methods and strategies used when multiplying whole numbers.

Multiplying large numbers can be cumbrous and demands computing whole number using various methods such as vedic, standard algorithm, finger manipulation, Cartesian product approach, area model, partial product algorithm (expanded notation), lattice (Gelosia), partitioning, compensation, the base-ten blocks array, to mention but a few. The data from the informants indicated that they used a variety of strategies that includes repeated 
addition, partitioning and compensation when teaching multiplication of whole numbers. Conversely, the findings from learners' exercise book shows that few learners employ other strategies such as long method, short method and learner invented strategies.

An extract from one of the learners' mathematics exercise book shows the vedic method of long multiplication in Figure 2 below.

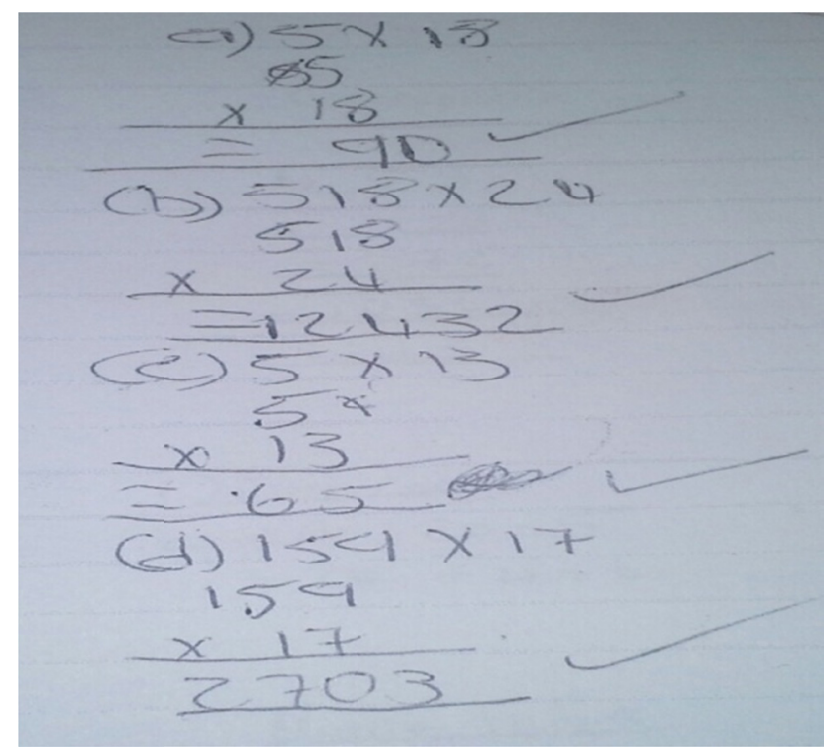

Figure 2. Grade 6 learner A's work on multiplication problems

The teachers' marking ticks showed that the learners' work was correct. However, the findings reveal that certain procedures were not followed in all the activities in Figure 2 above. The findings indicated that activities (a) and (c) where a single digit was multiplied by a two digit was done the other way round as if it was a two digit multiplied by a single digit as the two partial products were not indicated before writing the final answer. If the correct procedure had been followed learner A would have done activities (b) and (d) as illustrated in Figure 3 below. In addition it was also observed that the alignment of place values in activities (b) and (d) was not consistent.

As illustrated in Figure 2, the teacher did not write any comment(s) or make any correction based on the single step that was done by learner A. The assumption is that the learner might have done the calculations on a rough paper and only inserted the final answer. This shows that there was no emphasis from the teacher on steps to be followed to get to the final answer. In this case, to help this particular learner to understand multiplication better, the teacher could have employed the partial product algorithm as illustrated in Figure 3 instead of the Vedic methods that enables long multiplication to be carried out on one line.

Arguably the partial product algorithm method is computed by multiplying each digit in one factor by each digit in the other factor for example $5 \times 3=15$ and $4 \times 10=40$. The mathematics teacher should have emphasised the fundamental importance of place values. 


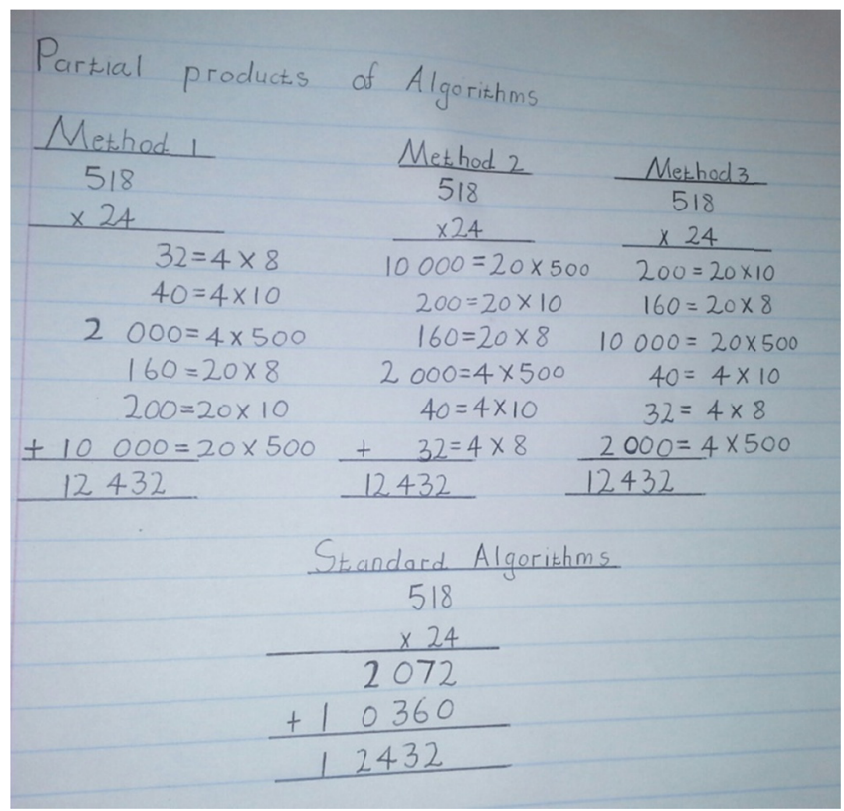

Figure 3. Grade 6 learner B's work on multiplying a three digit by two digit number

Learner B demonstrated two methods which are the partial products algorithm and the standard algorithm. The latter is the most widely used method in the Namibian mathematics classrooms and textbooks in use. This finding is similar to what Ilukena (2008) found out, that in most Namibian mathematics classes, teachers use the standard or traditional algorithm method whereby learners are drilled through a set of steps and procedures which lead to correct solutions without understanding.

Figure 3 shows the partial products algorithm methods 1, 2 and 3 or expanded algorithm for multi - digit multiplication that break the syndrome of working from right to left. In addition, partial products can also be written without place holders as long as non - zero digits stay in their correct place values. The partial products algorithm clearly identifies the value of each partial product as it is computed. It emerged in this study that some schools had attempted using the partial products algorithm without success as illustrated in Figure 2 above. The mathematics teachers should therefore be encouraged to emphasize that if each factor in the question assigned has a large number of digits then there is a large number of partial products. As shown in Figure 3 the partial products can be condensed by limiting them to just one for each digit in the second factor. This is done by combining partial products as they are being multiplied. This method is the standard algorithm for the multiplication of multiple digit questions. Therefore the partial products algorithm breaks the "old" right to left traditional way of multiplication of digits as this method can be worked out from left, center or right (Ilukena \& Utete, 2018; Kilpatrick et al., 2001).

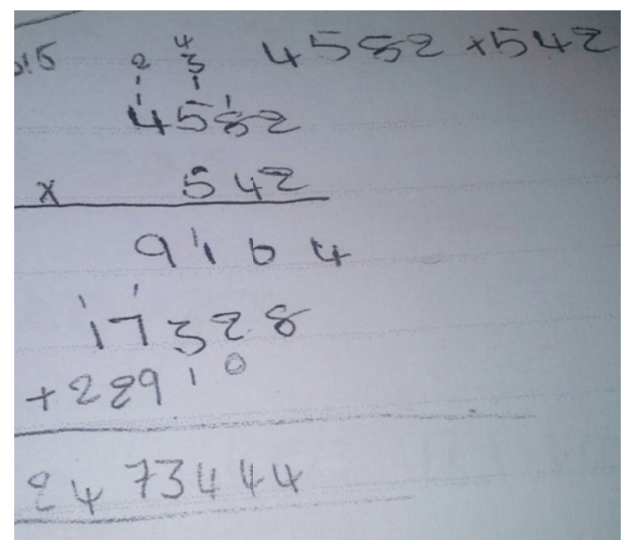

Figure 4. Grade 6 learner C's work of multiplying two multi-digit numbers 
Learner C's work illustrated in Figure 4 shows working from right to left and not considering the place value of tens thousands where the learner omitted the remainder of 2 after multiplying $4 \times 4=16+2=18$ which resulted in an incorrect answer. It should be noted that multiplying a three digit number is an extension of multiplying a two digit number while multiplying a two digit number is an extension of a single digit number. If these procedures had been correctly followed, understood, applied and practiced then the multiplication of the four digit number by a three digit number as illustrated in Figure 4 could have been solved correctly. This could imply that there is development of new understanding about multiplying thousand, hundred, tens and units. In addition, Lattice/Gelosia is another strategy that can be used to solve any of the activities illustrated in Figure 2.

\subsection{Lattice (Chinese) or Gelosia Multiplication Method}

In this method the digits to be multiplied are written along the columns and rows of a square or rectangle and the digits should be in their correct place values. The lattice is filled in by multiplying digit by digit, placing the tens digit in the upper triangle and ones digits in the lower triangle, then each diagonal is added down from the right to the left regrouping as necessary. The lattice multiplication method could also complement the worked activity (d) as illustrated in Figure 2. This would be done as illustrated by learner C's work in Figure 5 below in finding the product of 159 and 17.

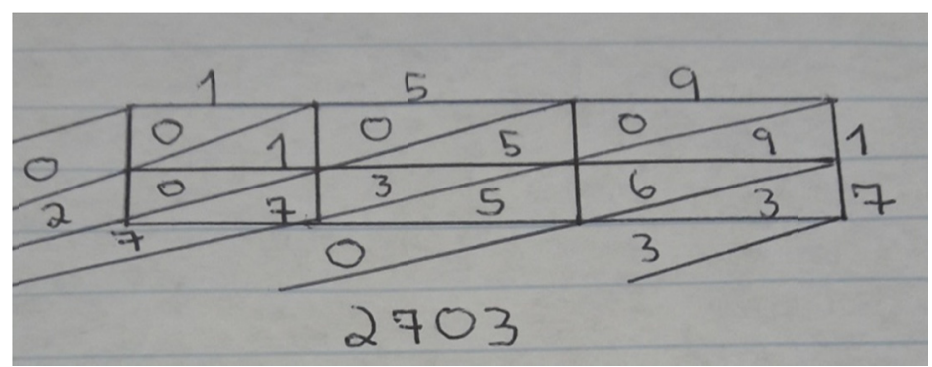

Figure 5. Learner C's work multiplying a three digit by two digit number using the lattice method

Finally, the product in the Lattice/Gelosia is read from left to right around the bottom of the lattice, this relates to the reading of other base numeration systems.

\subsection{Data Collected from Various Interactions with Stakeholders, Teachers, Students, Learners and Mathematics Congress Participants}

It should be pointed out that the use of different approaches to multiply whole numbers enable learners to choose a method that works for them instead of depending on one particular method used by the teacher. The findings from Ilukena and Utete since 2015 to date indicated that multiplying a single digit number by a single digit number works effectively using the finger-multiplication technique as one of the strategies that could be incorporated when using the lattice multiplication method by mathematics teachers to enhance the conceptual understanding of multiplication facts by learners (Ilukena \& Utete, 2018). The finger multiplication method was used in the schools under study, some schools in the two Kavango regions, with UNAM Rundu campus students, teachers from various schools, stakeholders during Rundu campus research day and participants from the mathematics congress. The finger - multiplication technique is a fun way of determining the multiples of $6,7,8$ and 9 . There are two variations of this strategy and both use fingers from both palms:

The first variation works with facts of 9 only, whereby fingers in both hands are spread apart and labeled 1 to 10 consecutively for example, 4 (Multiplier) $\times 9$ (Multiplicand), the fourth finger of the left hand palm is bent, then the product is read by counting fingers on left side of the bent finger as the ten digit (3) then fingers to the right side of the bent fingers as the ones digit (6) this equates to 36 .

The second variation deals with numbers $6,7,8$ and 9 rather than 1 to 5 which are easy to recall. The procedure is as follows:

- Each standing finger on each palm represents a ten (10) and the folded finger on each palm represents ones (single digits)

- For example to find the answer to $9 \times 9=81$

(i) Raise the hands with the palms facing you. 
(ii) From both palms subtract 9 from 10 .

(iii) Left palm: $10-9=1$; Right palm: $10-9=1$.

(iv) The answers in (iii) inform us on how many fingers we need to fold on each palm.

(v) In this case you fold the little finger on each palm and multiply them which in our case is $1 \times 1=1$.

(vi) Add the standing fingers which in our case become $40+40=80$.

(vii) To find the final answer you add the answers from (v) and (vi) which in this case is $1+80=81$.

The findings from the usage of the finger-multiplication technique revealed that this method was used to advance the understanding of multiplication in solving the lattice multiplication method. It also further enhanced the commutative law/rule of multiplication as shown in Figure 5. The findings from the interaction with learners during the presentation of the finger - multiplication technique indicated that solutions to mathematical problems could also be achieved by using other strategies not only the teachers' methods. This augments the understanding of multiplication, after which the mathematics teachers can then resort to the use of the multiplication fact tables of $10 \times 10$ or $12 \times 12$ and make multiplication facts automatic and efficient. By the same token, other methods that emerged were:

Area Model to multiply single digit numbers

The following steps can be used to multiply $5 \times 3$

i) Draw a rectangle or a square as shown

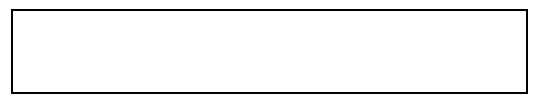

ii) Divide the rectangle or square in 5 columns as shown below

iii) Divide the figure in (ii) in 3 rows as shown

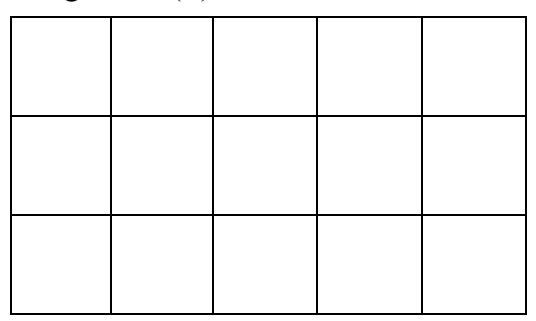

iv) Count all the small rectangles in (iii)

v) Therefore $5 \times 3=15$

This multiplication array 5 by 3 can be described as 5 rows of $3 \mathrm{~s}$ or 3 rows of $5 \mathrm{~s}$. In both cases, the answer is 15 . Learning with a strong conceptual understanding of the commutative property is very important in basic fact mastery, as it cuts the facts to be memorized in half.

\subsection{Cartesian Product Approach}

The definition of whole number multiplication (Cartesian Product Approach) implies that if $a$ and $b$ are any two whole - number where $a=n(A)$ and $b=n(B)$ then $a^{*} b=n(A * B)$. For example to show that $2 \times 3=6$, we represent each number as a set. Let the total number of elements (Cardinality) in set $A$ and set $B$, be represented by $A=\{a, b\}$ and $\mathrm{B}=\{1,2,3\}$, then $\mathrm{n}(\mathrm{A})=2$ and $\mathrm{n}(\mathrm{B})=3$ and $2 \times 3=\mathrm{n}(\mathrm{A} \times \mathrm{B})$

$=\mathrm{n}\{(\mathrm{a}, \mathrm{b}) \times(1,2,3)\}$

$=\mathrm{n}(\{(\mathrm{a}, 1),(\mathrm{a}, 2),(\mathrm{a}, 3),(\mathrm{b}, 1),(\mathrm{b}, 2),(\mathrm{b}, 3))\}$

Then count the number of ordered pairs in the set $=6$, therefore $2 \times 3=6$.

The Cartesian product approach can be modeled in two ways with sets and tree diagrams, which lead to advanced mathematics in set theory and statistics.

\subsection{Data from Questionnaires}

Furthermore, it also emerged from questionnaires that improving learners' proficiency and understanding of the multiplication facts require the following: 


\subsection{Giving Time to Instruction}

The findings from the questionnaires shows that all the ten mathematics teachers revealed that learners spent little or no time at all in learning and revising mathematics probably due to lack or sharing of textbooks, lack of motivation, fear for mathematics, lack of consultation or tutorials, and lack of parental assistance when learners do their mathematics homework, projects and assignments. For mathematics proficiency to be developed, substantial time should be devoted to instruction. At least one hour each school day, should be devoted to each unit and topic to enable learners develop understanding of concepts and procedures involved in solving mathematical problems. In addition, time should be apportioned in such a way that all strands of mathematical proficiency including conceptual understanding, procedural fluency, strategic competence, adaptive reasoning and productive disposition receive adequate attention in Namibian primary schools.

\subsection{Giving Learners Time to Practice Taught Procedures}

Practice is important in the development of mathematical proficiency. Kilpatrick et al. (2011) show that when learners have multiple opportunities to use the computational procedures, reasoning processes, and problem-solving strategies that they are learning, the methods that they are using become smoother, more reliable, and better understood. However, it should be noted that practice alone is not enough to ensure understanding of the taught content; it needs to be built on understanding and accompanied by proper feedback to support all the five strands of mathematics proficiency and not only procedural fluency. Practice on computation procedures should be designed to extend learner understanding. Moreover, the ability to solve a problem is a highly priced skill in learners' lives and there are no hard and fast rules that will ensure success in solving problems in mathematics (Alfred, 2014). In addition, according to (Polya, 1957 as cited by Stewart, Redin, \& Watson, 2012, p. 1 as well as Freitag, 2014, p. 44) there are procedures to be followed in problem solving such as understanding the problem, devising a plan, carrying out the plan and looking back that may prove useful in ensuring learners becoming competent in problem solving.

\subsection{Mathematics School Cluster Model}

The data from the ten Mathematics teachers in this study divulged that the school cluster system that started in 1996 in the Kavango Education region failed due to lack of coordination and financial constraints. The main aim was to train and upgrade skills of Lower primary and Life Science teachers (Dittmar, Mendelesohn, \& Ward, 2002) and it was replicated to other subjects (p1.). The benefits of the school cluster system included improving quality of teaching and learning by sharing resources, experiences, empowering teachers at cluster level to become experts in their areas of specialization as well as facilitating administration and the pooling of resources from several small schools.

However, research by Nwagbara and Edet (2013) has shown that re-training of mathematics teachers is a crucial area of teacher preparation that needs more attention in any educational system. In the same vein the Mathematics teachers who were qualified upper primary mathematics teachers still needed to be re-trained adequately and positioned to ensure quality teaching, to raise performance levels, update mathematical scope, sharpen skills and methodology, improve instructional skills and practices, increase literacy and numeracy levels as well as assist them in making better decisions and increased job satisfaction in preparation for the new revised mathematics curriculum. These factors are aimed at empowering mathematics teachers to have a more positive impact in their classrooms, encourage them to implement new teaching and learning methods, to improvise teaching and learning materials to enhance learner-centred techniques that will enable learners to become critical thinkers, problem solvers and to become self-sufficient.

The advocacy for the school cluster model in this paper is based on the re-training and professional development based on mathematics teachers and school cluster model. The model is effective and efficient compared to the cascade approach. The cascade model is a one time workshop of 5 days per year and dissemination of acquired knowledge and skills is not frequently passes to other teachers who did not attend the workshop (Musset, 2010 as cited in Nwagbara, 2014. p. 13). The school cluster model is highly effective and efficient in sense that it brings teachers together, facilitate a process where the mathematics teachers become creative in problem-solving, lesson preparation, production of teaching and learning materials, class management, evaluation and assessment and other pedagogical skills. It also enhances teacher support, guidance, expert mentoring, and exposes both seasoned and novice teachers to current educational trends. They also plan lessons together, observe one another as they teach while others serve as mentors and analyse learners' work collectively. In addition this encourages collaborative works, enhances confidence and gives the value of working with peers to achieve their set teaching goals.

Learners need to be actively involved in mathematical activities for the effectiveness of the structured problem 
solving instructional approach which is designed to create interest in mathematics and stimulate creative mathematical activities in the classroom through learners' collaborative work. This approach follows three major characteristics which are carefully selected word problems, activities and their cohesiveness, extensive discussions; and emphasis on chalk board practices.

In summary the findings in this study reveal that there are varieties of strategies that are available to mathematics teachers that they can employ in order to enhance the understanding of the basic Mathematics facts at the primary school level.

\section{Conclusion}

It is evident from this research that multiplication is one of the basic operations that is not being well addressed in primary schools in Kavango East and West regions. The findings in this paper indicated that some Mathematics teachers in the study still resorted to the standard algorithm without allowing learners to apply their own invented strategies to make multiplication easier and fun. Our findings indicated that they are various instructional approaches used in the teaching of multiplication such as Cartesian product, area model, lattice, fingers, standard algorithm, partial product algorithm and expanded algorithm. From the data that was gathered it is evident that the mathematics lessons that involve multiplication activities should start with learners working individually using their own prior mathematical knowledge, after that the teacher and learners discuss as a whole class to compare different individual approaches and solutions to the activities. This whole class activity discussion provides learners with vast opportunities in conceptual understanding of multiplication facts and application of different approaches.

\subsection{Implications}

This study has implications for mathematics teachers, Mathematics Advisory teachers, curriculum developers, mathematics school cluster teachers, professional development programme coordinators and other educational stakeholders with regards to the teaching of multiplication at primary school level. . We therefore recommend that:

1) The five mathematical proficiency strands: conceptual understanding, procedural fluency, strategic competency, adaptive reasoning and productive disposition be explicitly stated in the Namibian Mathematics Curriculum.

2) Other instruction methods and strategies such as multiplication using fingers, partial product algorithm, Cartesian product approach, Russian method, area model, lattice (Chinese) Multiplication method should be used in the teaching of multiplication in primary schools in Namibia. Teachers at this level need to be introduced to these methods during their teacher preparation programmes.

3) An intervention programme should be developed by the researchers to implement the suggested instruction methods and strategies.

4) The Department of Mathematics, Science and Sport Education at the University of Namibia, Rundu campus should provide Continuous Professional Development (CPD) to primary school mathematics teachers in the Kavango East region so as to make them proficient at teaching multiplication using different methods and strategies.

5) Mathematics advisory teachers should provide guidance to primary mathematics teachers on strategies that could be used to enhance learner understanding of multiplication.

6) Mathematics School Clusters should be of accessible distance from each other so as to reduce stress, costs, time and risks involved in travelling long distances as compared to travelling long distances to attend workshops, conferences, symposia and seminars that only benefit a few selected individuals.

\section{References}

Alfeld, P. (2014, June 5). Understanding mathematics. Department of Mathematics, University of Utah. Retrieved from http://www.math.utah.edu/ pa/math/polya.html

Baroody, A. J. (2006). Why children have difficulties mastering the basic fact combinations and how to help them. Teaching children mathematics, 13(1), 22-31.

Brendefur, J., \& Strother, S. (2011). Developing mathematics thinking: Geometry workbook. Retrieved from http://www.cocld.org/doc/aDMT\%20K-8\%20Workbook\%20Geometry\%202-13-2011.pdf

Brendefur, J., Strother, S., Thiede, K., \& Appleton, S. (2015). Developing multiplication fact fluency. Advances in Social Sciences Research Journal, 2(8), 142-152. https://doi.org/10.14738/assrj.28.1396

Brownell, W. A., \& Chazal, C. B. (1935). The effects of premature drill in third-grade arithmetic. The Journal of 
Educational Research, 29(1), 11-28. https://doi.org/10.1080/00220671.1935.10880546

Dittmar, F., Mendelesohn, J., \& Ward, V. (2002). The school cluster system in Namibia: Framework for quality education. Windhoek. Retrieved from http://www.raison.com.na/school\%20cluster\%20in\%20Namibia.pdf

Freitag, A. M. (2014). Mathematics for elementary school teachers: A process approach. Brooks/Cole, Cengage Learning.

Harden, R. M. (1999). What is a spiral curriculum? Medical teacher, 21(2), 141-143. https://doi.org/10.1080/01421599979752

Henry, V. J., \& Brown, R. S. (2008). First-grade basic facts: An investigation into teaching and learning of an accelerated, high-demand memorization standard. Journal for Research in Mathematics Education, 39(2), $153-183$.

Ifrah, G. (1988). The universal history of numbers. London: Harvill.

Ilukena, A. M. (2008). A need analysis for the implementation of a complementary course in mathematics education for teachers of Mathematics in Namibia: A case study of the BETD graduates (Unpublished masters' thesis). Grahamstown: Rhodes University.

Ilukena, A. M., \& Utete, N. C. (2015, April 28). Enhancing the understanding of multiplication using fingers at Primary schools in the Kavango Regions. A paper presented at the 10th Annual National Mathematics Congress, Swakopmund.

Ilukena, A. M., \& Utete, N. C. (2018, May 2). Strategies on computing multiplication. A paper presented at the 1st Kavango East Regional Mathematics Congress held at Rundu Vocational Training Centre, from 1st-3rd May 2018, Rundu.

Kilpatrick, J., Swafford, J., \& Findell, B. (2001). Adding it up: Helping children learn mathematics. Washington DC: National Academy Press.

Kolpas, J. S. (2002, April 7). Let your fingers do the multiplying. National Council of Teachers of Mathematics, 95(4), 246-251. Retrieved from https://www.dccc.edu/sites/default/files/faculty/sid_kolpas/mathteacherfingers.pdf

Kumon Education Company. (2012, July 3). The importance of learning basic multiplication and division from a young age. Japan. Retrieved from http://www.kumon.co.uk/blog/the-importance-of-learning-multiplicationand-division-from-a-young-age/

Lerman, S. (1994). Critical/humanistic mathematics education: A role for history? In M. Selinger (Ed.), Teaching mathematics (pp. 97-102). Routledge. 11 New Fetter Lane: London.

Mateya, M., Utete, C. N., \& Ilukena, A. (2016). Factors that cause poor performance in mathematics at national school secondary certificate level compared to junior secondary certificate level in four selected schools in the two Kavango Educational Regions. Journal for studies in humanities and social sciences, 5(2), 108-115.

Ministry of Education, Arts \& Culture. (2015). Senior Primary Phase mathematics syllabus Grades 4-7. National Institute for Educational Development (NIED): Okahandja.

Ministry of Education, Arts \& Culture. (2016). Senior Primary Phase mathematics syllabus Grades 4-7. National Institute for Educational Development (NIED): Okahandja.

National Council of Teachers of Mathematics (NCTM). (1989). Historical Topics for the mathematics classroom. Reston, VA: NCTM.

Nwagbara, A. C. (2014). The effectiveness of teachers and school cluster model for primary school mathematics teachers' professional development in Cross River State, Nigeria. Asia Pacific Journal of Education, Arts and Sciences, 1(3), 12-19. Retrieved from http://apjeas.apjmr.com/wp-content/uploads/2014/07/APJEAS2014-1-040.pdf

Nwagbara, A. C., \& Edet, E. O. (2013). Re-training for production of quality secondary school mathematics teachers in Cross River State. Paper presented at association of Nigerian teachers (ASSONT) 8th Annual National Conference, Enugu.

Southern, J. F., Galfalvi, F., Gjertsen, D., Illingworth, V., Issacs, A., Jackson, T., \& Stewart, I. (1989). The multiplication concept. In J. Daintith, \& R. D. Nelson (Eds.), Dictionary of mathematics (pp. 224-225). Penguin, London.

Stewart, J., Redin, L., \& Watson, S. (2012). Pre-calculus mathematics for calculus: International Edition (6th 
ed.). Brooks/Cole Cengage Learning. Belmont: USA.

Takahashi, A. (2000). Current trends and issues in lessons in Japan and the United States. Journal of Japan Society of Mathematical Education, 82(12), 15-21.

Takahashi, A. (2006). Characteristics of Japanese mathematics lessons. Tsukuba journal of educational study in mathematics, 25(1), 37-44.

Van de Walle, J. A., Karp, S. K., \& Bay-Williams, J. M. (2010). Elementary \& middle school mathematics: Teaching developmentally (7th ed.). Pearson: USA.

Van de Walle, J. A., Karp, S. K., \& Bay-Williams, J. M. (2012). Elementary \& middle school mathematics: Teaching developmentally (8th ed.). Pearson: USA.

Vygotsky, L. S. (1978). Mind in society: The development of higher psychological processes. Cambridge, Mass.: Harvard University Press.

Wilson, C., McLaughlin, T. F., \& Bennett, A. (2016). Using DI Flashcards with a Count-By Series Procedure with a Fourth Grade Student with ADHD and Learning Issues in a Resource Room Setting Math Facts with an Evaluation of Generalization to New Math Facts. Asian Education Studies, 1(1), 23. https://doi.org/10.20849/aes.v1i1.6

Winter, J. (2001). 13 Personal, spiritual, moral, social and cultural issues in teaching mathematics. Issues in mathematics teaching, 197.

\section{Copyrights}

Copyright for this article is retained by the author(s), with first publication rights granted to the journal.

This is an open-access article distributed under the terms and conditions of the Creative Commons Attribution license (http://creativecommons.org/licenses/by/4.0/). 